\title{
Preface: The importance of small water bodies
}

\author{
Mary Kelly-Quinn $\cdot$ Jeremy Biggs $\cdot$ Stefanie von Fumetti
}

Received: 3 November 2016/Revised: 3 November 2016/ Accepted: 10 December 2016/Published online: 3 January 2017

(C) Springer International Publishing Switzerland 2016

Worldwide, there is growing interest in the role of small water bodies, such as springs, headwater streams, ponds, small lakes and ditches, in catchment ecology, biodiversity and provision of ecosystem services. Associated with this is increasing recognition amongst researchers and regulators in Europe, North America and elsewhere that their protection and management are of considerable importance. Alpine springs, for example, are special ecotones as species have to adapt to extremely low temperatures and a short growth season during summer. Intermittent springs, which occur frequently in the Mediterranean and in karstic regions, lack hydrogeological stability. Headwater streams support a large proportion of catchment biodiversity and influence downstream

Guest editors: Mary Kelly-Quinn, Jeremy Biggs \& Stefanie von Fumetti / The Importance of Small Water Bodies: Insights from Research

M. Kelly-Quinn ( $\square)$

School of Biology and Environmental Science, University College Dublin, Belfield, Dublin 4, Ireland

e-mail: mary.kelly-quinn@ucd.ie

\section{J. Biggs}

Freshwater Habitats Trust, Bury Knowle House, Oxford, UK

S. von Fumetti

Department of Environmental Sciences, University of

Basel, Basel, Switzerland water quality, while small lakes and ponds contribute significantly to regional biodiversity. All are particularly sensitive to land use and other anthropogenic inputs. However, small water bodies in Europe and other regions have still received relatively little research attention. This may in part relate to the fact that they do not strictly fall within the monitoring requirements of the Water Framework Directive and other similar legislation. These concerns were the impetus for the organisation of a special session on 'Small Water Bodies - knowledge base, importance, threats, and future research priorities' at the 9th Symposium for European Fresh Water Sciences (SEFS) in Geneva, July 2015. The session aimed to refocus research attention on these resources by drawing together expertise on small water bodies within Europe to review the scientific knowledge base, in particular their contribution to overall ecological integrity of aquatic systems, to highlight threats to their physical, chemical and ecological status and to identify research priorities.

This special issue of Hydrobiologia includes thirteen of the papers presented at SEFS and one additional invited contribution, covering both flowing and standing waters. The issue opens with a broad review of the importance of small water bodies and priorities for research to underpin better protection of small waters. A second review paper presents a global perspective of the current state of knowledge regarding the ecological impacts of climate change and 
catchment land use on small tropical streams, and here again highlights knowledge gaps. While most of the other papers are dealing with European systems, two papers are included on studies in South America and Africa. Apart from the two review papers, a wide range of more specific topics are covered ranging from the phosphorus retention capacity of small streams to factors governing thermal responses in high-elevation springs.
Having compiled this selection of papers and from other ongoing activities in this area, it is clear that considerable knowledge gaps remain to be addressed across both small lentic and lotic waters, and these should be highlighted to funding agencies as priorities for research. In parallel, policy actions are needed to better integrate small waters into the management of catchments and landscapes. 